\title{
Guidance of Neuronal Growth Cones in the Grasshopper Embryo. IV. Temporal Delay Experiments
}

\author{
Chris Q. Doe, Michael J. Bastiani, and Corey S. Goodman \\ Department of Biological Sciences, Stanford University, Stanford, California 94305
}

In the previous 3 papers, we demonstrated that neuronal growth cones display selective affinities for both specific axonal and glial pathways in the grasshopper embryo; for example, the pCC growth cone selectively recognizes the MP1/dMP2 axons, while the aCC growth cone selectively recognizes the $\mathrm{U}$ axons and a specific glial cell (the segment boundary cell).

We were interested in further testing the temporal specificity of these affinities. To address this issue, we performed specific temporal transplant experiments by using a laser microbeam in ovo to ablate the neuronal precursor cell, neuroblast (NB) 1-1, that generates the aCC and pCC neurons. Neighboring ectodermal cells regulate and replace the ablated NB 1-1; the new NB 1-1 then generates the aCC and pCC neurons with a temporal delay of 10-20 hr (2-4\% of development), depending upon the experimental paradigm.

The results of these temporal delay experiments further demonstrate the selective affinities of the aCC and pCC growth cones for specific axonal and glial surfaces and confirm that these specificities are absolute and not hierarchical. Furthermore, they suggest that precise timing is not important; both the pCC and aCC growth cones are able to selectively recognize their appropriate axonal and glial pathways after delays of 10-20 hr despite being confronted with the surfaces of many additional axons and pathways.

Our previous experimental analysis indicated that neuronal growth cones display selective affinities for specific axonal pathways; for example, the pCC growth cone specifically recognizes the MP1/dMP2 fascicle (paper I) and the aCC growth cone recognizes the $U$ fascicle (paper II). The results from cell ablation experiments argue against (1) the simple location of axons, (2) the simple timing of axon outgrowth, and (3) simple quantitative differences in the expression of a common surface label as the major determinant in the selective affinities of the aCC and pCC growth cones. Rather, the results suggest that the aCC growth cone displays an absolute preference for the $U$ axons, and the pCC growth cone an absolute preference for the MP1/dMP2 axons.

These results support the labeled-pathways hypothesis (Bastiani et al., 1984b; Goodman et al., 1982; Raper et al., 1983ac, 1984). Moreover, they suggest that the surfaces of the MP1/ dMP2 axons and the $U$ axons express specific recognition labels that allow the aCC and pCC growth cones to distinguish among them and other axon fascicles that develop within the embryonic neuropil.

\footnotetext{
Received Feb. 18, 1986; revised Apr. 25, 1986; accepted May 5, 1986.

We thank Frances Thomas for technical assistance. This research was supported by an NICHHD Traineeship (C.Q.D.), a Scholars Award from the F.E.S.N. Foundation (M.J.B.), and grants and awards from the NIH, NSF, March of Dimes, and the McKnight Foundation (C.S.G.).

Correspondence should be addressed to Corey S. Goodman at the above address. Copyright (C) 1986 Society for Neuroscience $0270-6474 / 86 / 123552-12 \$ 02.00 / 0$
}

We were interested in further testing the temporal and spatial specificity of these affinities. How important is timing? Do the $\mathrm{MP} 1 / \mathrm{dMP} 2$ and $\mathrm{U}$ axons continue to express throughout development the surface labels used for the guidance of the $\mathrm{pCC}$ and aCC growth cones, respectively? Once many other axons and fascicles have developed, can the pCC and aCC growth cones still selectively recognize their appropriate axon pathways? If these growth cones extend into other regions of the developing neuropil, will they follow other fascicles? And finally, if these growth cones contact their normal pathways but at different times, locations, and orientations, will they still recognize them?

To answer these questions, we performed specific temporal transplant experiments using a laser microbeam to ablate in ovo the neuronal precursor cell (NB 1-1) that generates the aCC and pCC neurons. We knew that neighboring ectodermal cells would regulate and replace the ablated NB 1-1, and that this new NB 1-1 would generate the aCC and $\mathrm{pCC}$ neurons with a temporal delay of 10-20 hr (2-4\% of development), depending upon the experimental paradigm (Doe and Goodman, 1985a, b).

The results of these temporal delay experiments further demonstrate the selective affinities of the aCC and pCC growth cones for specific axonal surfaces and confirm that these specificities are absolute and not hierarchical. They further suggest that precise timing is not important; both the pCC and aCC growth cones are able to selectively recognize their appropriate axonal pathways (and the aCC its appropriate glial pathway) after a delay of 10-20 hr (2-4\% of development). Moreover, although the aCC displays no affinity for any of the other axons within the developing ganglionic neuropil (up to 100 different axons in 25 fascicles), it can still recognize its appropriate pathway in the next anterior segment even though it contacts this pathway at a different time, location, and spatial orientation than normal. Some of these results have been briefly reviewed previously (Bastiani et al., 1985; Doe et al., 1985).

\section{Materials and Methods}

All methods used in this paper are described in the first paper in this series.

\section{Results}

\section{Generation of the aCC and pCC neurons}

The generation of the $\mathrm{aCC}$ and $\mathrm{pCC}$ neurons during grasshopper neurogenesis has previously been studied in great detail (Doe and Goodman, 1985a, b; Doe et al., 1985; Kuwada and Goodman, 1985). The generation of these and other identified neurons from the neurogenic region in each segment involves 2 major stages (Fig. 1). In the first stage, the morphologically uniform ectodermal sheet produces a stereotyped array of NBs (Bate, 1976; Wheeler, 1893). In the second stage, each NB within this array divides asymmetrically to generate a characteristic chain of progeny, called ganglion mother cells (GMCs), each of which 

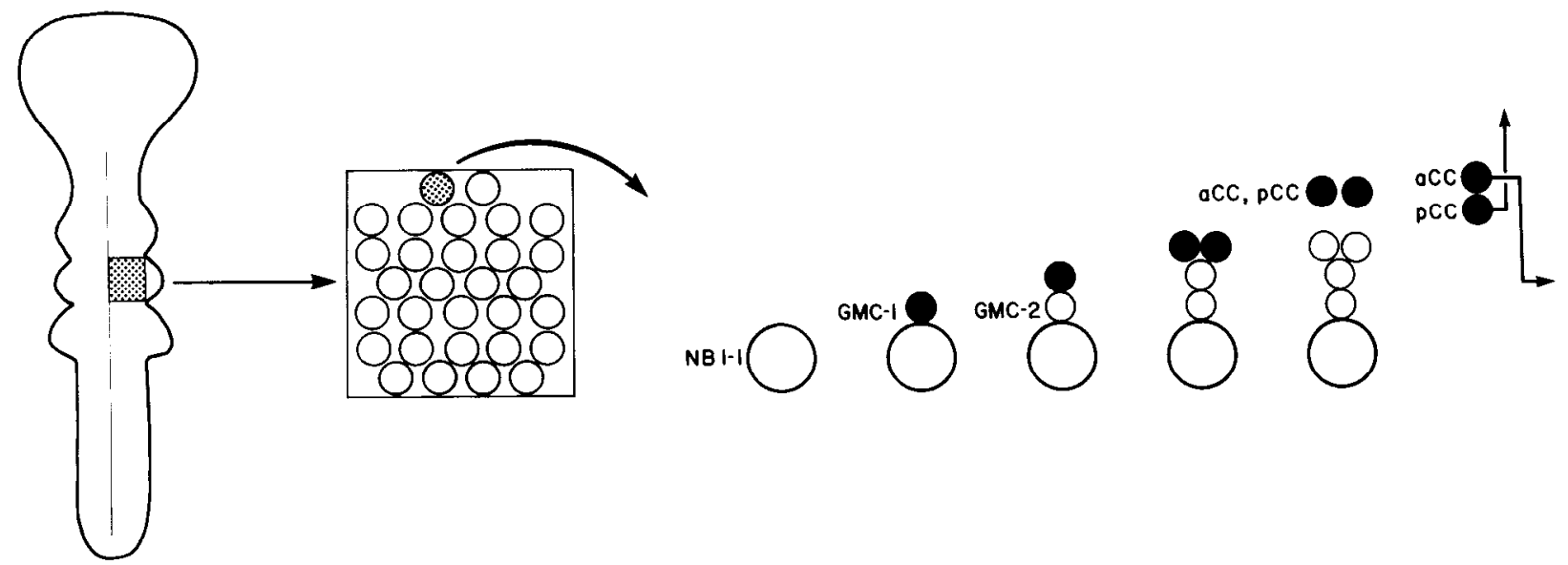

Figure 1. Schematic diagram showing the 2 major steps in grasshopper neurogenesis. The first step (left) is the transformation in each hemisegment of a sheet of $\sim 150$ ectodermal cells into a stereotyped pattern of 30 unique neuronal precursor cells (neuroblasts; NBs); the remaining cells become non-neuronal support cells or die. The second step of neurogenesis (right) is the production of a characteristic family of neurons from each NB. Each NB divides asymmetrically to generate a chain of ganglion mother cells $(G M C S)$, which divide once symmetrically to produce a pair of postmitotic neurons. The lineage of $N B 1-1$ (shaded in middle box) is illustrated; the first ganglion mother cell (GMC-I) from $N B 1-I$ divides to generate the $a C C$ and $p C C$ neurons.

divides symmetrically once more to generate a pair of sibling cells (which differentiate into neurons) (Fig. 1). Each of the NBs can be individually identified by its time of formation and position within the array, and according to the identified neurons that it generates (e.g., Goodman and Spitzer, 1979; Raper et al., 1983a; Taghert and Goodman, 1984).

NB 1-1 generates GMC-1 (from its first division), which divides once more to produce a pair of sibling cells that differentiate into the identified aCC and pCC neurons (Fig. 1) (Goodman et al., 1982, 1984). The paradigms for the experiments described here are based on 2 important observations from previous laser ablation experiments (Doe and Goodman, 1985b): (1) The ablated NB 1-1 can be replaced by neighboring (undifferentiated) neural ectodermal cells (nECs), and (2) the replaced NB 1-1 and its subsequent progeny are generated with a time delay of from 2 to $4 \%$, depending on the experimental paradigm, as described below.

\section{Experiment 1}

We ablated NB 1-1 before its first division (Fig. 2A). All ablations were carried out in ovo, using a laser microbeam; only the target NB was affected, and the embryos continued normal development in their egg cases. A neighboring, undifferentiated nEC replaced the ablated NB 1-1. The regulated NB 1-1 generated a GMC-1, which divided to produce the aCC and $\mathrm{pCC}$ neurons. In so doing, the generation of the aCC and $\mathrm{pCC}$ neurons was delayed by about $10 \mathrm{hr}$ ( $2 \%$ of embryonic development) compared with their normal time of generation (Doe and Goodman, 1985b).

In this and all subsequent experimental paradigms, the delayed aCC and pCC neurons have migrated anteriorly across the segment border to their normal locations (see Fig. 3 in papcr I of this series). They then extend growth cones, which are confronted with additional axons because of the temporal delay. Nevertheless, in all the experimental embryos using this paradigm $(n=9)$, the growth cones of the delayed aCC and $\mathrm{pCC}$ neurons made the same pathway choices as normal; the pCC extended anteriorly along the MP1/dMP2 fascicle, and the aCC extended posteriorly along the $U$ fascicle and then turned laterally along the intersegmental nerve. An example of such an experimental embryo is shown in Figure $2 A$.

We wanted to know the cellular environment and contacts of the $\mathrm{pCC}$ and aCC growth cones during these delayed pathway choices and the specific surfaces upon which the growth cones were extending. Semiserial-section reconstructions of experimental embryos at different ages were used to examine these factors. Data from 2 such reconstructions are shown for experiment 1: a "younger" assay in Figure 3, $A$ and $B$, and an "older" assay in Figure 4.

The "younger" assay (Fig. 3, $A, B$ ) is of an experimental embryo in which the delayed aCC growth cone had just turned posteriorly along the $\mathrm{U}$ fascicle. The aCC first extended laterally just under the basement membrane (Fig. $3 A$ ). The basement membrane, at this stage, still appeared much as it does in normal embryos when the aCC growth cone turned toward the U fascicle; this was in contrast to $1-2 \%$ later in development, when additional glial cells populated the area just under the membrane and the fascicles dropped further ventrally (Fig. 3C).

The aCC growth cone then turned posteriorly along the $\mathrm{U}$ fascicle, also keeping contact with the basement membrane and/ or processes just under it. At this stage, each of the first 3 longitudinal fascicles (vMP2, MP1/dMP2, and U) contained several additional axons. A third $U$ axon then joined the initial 2. We identified this particular axon as a $U$ axon because it originated from a cell body located next to the initial $2 \mathrm{U}$ cell bodies and its axon followed the initial $2 \mathrm{U}$ axons dorsally towards the connective.

The "older" assay (Fig. 4) is of an experimental embryo, 2\% older than that described above, in which the delayed aCC growth cone had extended posteriorly and already turned laterally out the intersegmental (IS) nerve. By this stage of development, the initial 3 fascicles in the connective had already begun to expand into the 3 superfascicles, I, II, and III, by the addition of many more axons (Bastiani et al., 1984a; Bastiani et al., 1986), and are so labcled in Figure 4. In the ganglionic neuropil (not shown), these additional axons formed several new fascicles. We identified the aCC axon and the $3 \mathrm{U}$ axons in a semiserial reconstruction of this embryo.

Where the aCC axon first joined the $U$ fascicle anteriorly near its cell body (Fig. 4A), the aCC axon was in contact with the three $U$ axons (Fig. $4 B$ ). Further posteriorly, the aCC axon was in contact with a process of the segment boundary cell (SBC; see paper III), which, in turn, was in contact with the $3 \mathrm{U}$ axons (Fig. 4, $C, D$ ). The aCC axon turned laterally along the pathway of the intersegmental nerve, while the 3 superfascicles, I, II, and III, continued longitudinally to the next segment (Fig. $4 E$ ). In- 


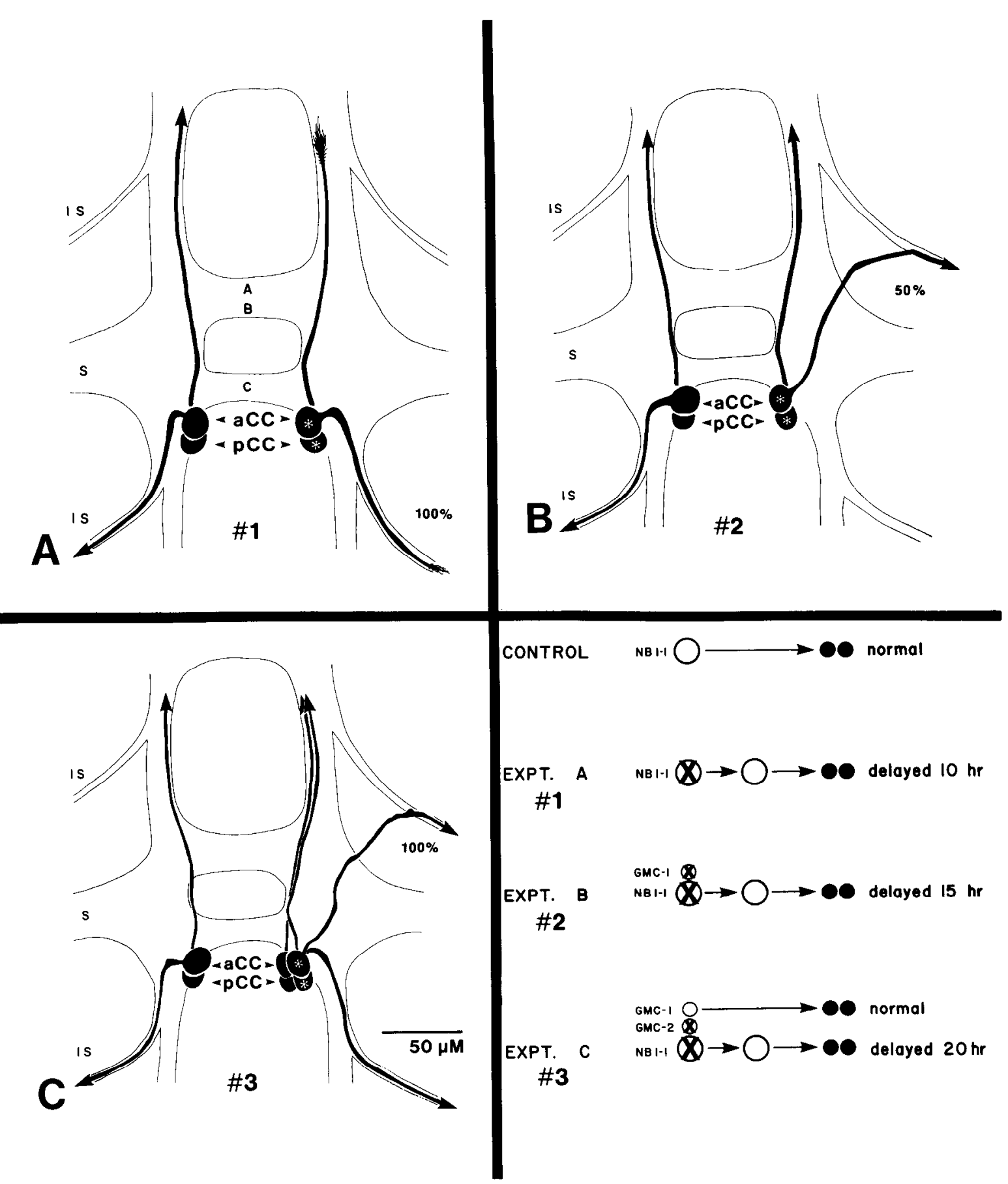

Figure 2. Schematic diagram showing the 3 paradigms used for temporal delay experiments (see panel, lower right), and camera lucida drawings of the $a C C$ and $p C C$ neurons [filled with Lucifer Yellow (LY) and visualized with an anti-LY antibody and HRP immunocytochemistry] in a typical example from each experimental paradigm $(A-C$; asterisks denote delayed $a C C$ and $p C C$ neurons; $I S$, intersegmental nerve; $S$, segmental nerve). Normally, the first ganglion mother cell $(G M C-I)$ from $N B 1-1$ divides to produce the $a C C$ and $p C C$ neurons. A, In experiment 1 , NB 1-1 was ablated before its first division. A neighboring, undifferentiated neural ectodermal cell (nEC) took the place of the ablated NB 1-1. The regulated NB 1-1 generated a GMC-1, which divided to produce the $a C C$ and $p C C$ neurons with a delay of about $10 \mathrm{hr}(2 \%$ of embryonic development). $B$, In experiment 2, both NB 1-1 and its first progeny (GMC-1) were ablated. The new (regulated) NB 1-1 generated a GMC-1, which divided to produce the $a C C$ and $p C C$ neurons. In this case, the generation of the aCC and pCC neurons was delayed by about $15 \mathrm{hr}$ (3\%) compared with their normal time of generation. In $50 \%$ of the experiments the $a C C$ grew anteriorly, as shown. The other $50 \%$ grew posteriorly as normal, extending out the $I S$ nerve of their own segment. $C$, In experiment 3, both NB 1-1 and GMC-2 were ablated. The original GMC-1 divided to produce normal $a C C$ and $p C C$ neurons. The ablated NB 1-1 was replaced and the ncw NB 1-1 bcgan its lincage ancw. Although delayed by some $20 \mathrm{hr}(4 \%)$, the regulated NB 1-1 nevertheless generated a new GMC-1, thus giving rise to a second, duplicate pair of aCC and pCC neurons; both pairs survived and differentiated. See text for further discussion. 


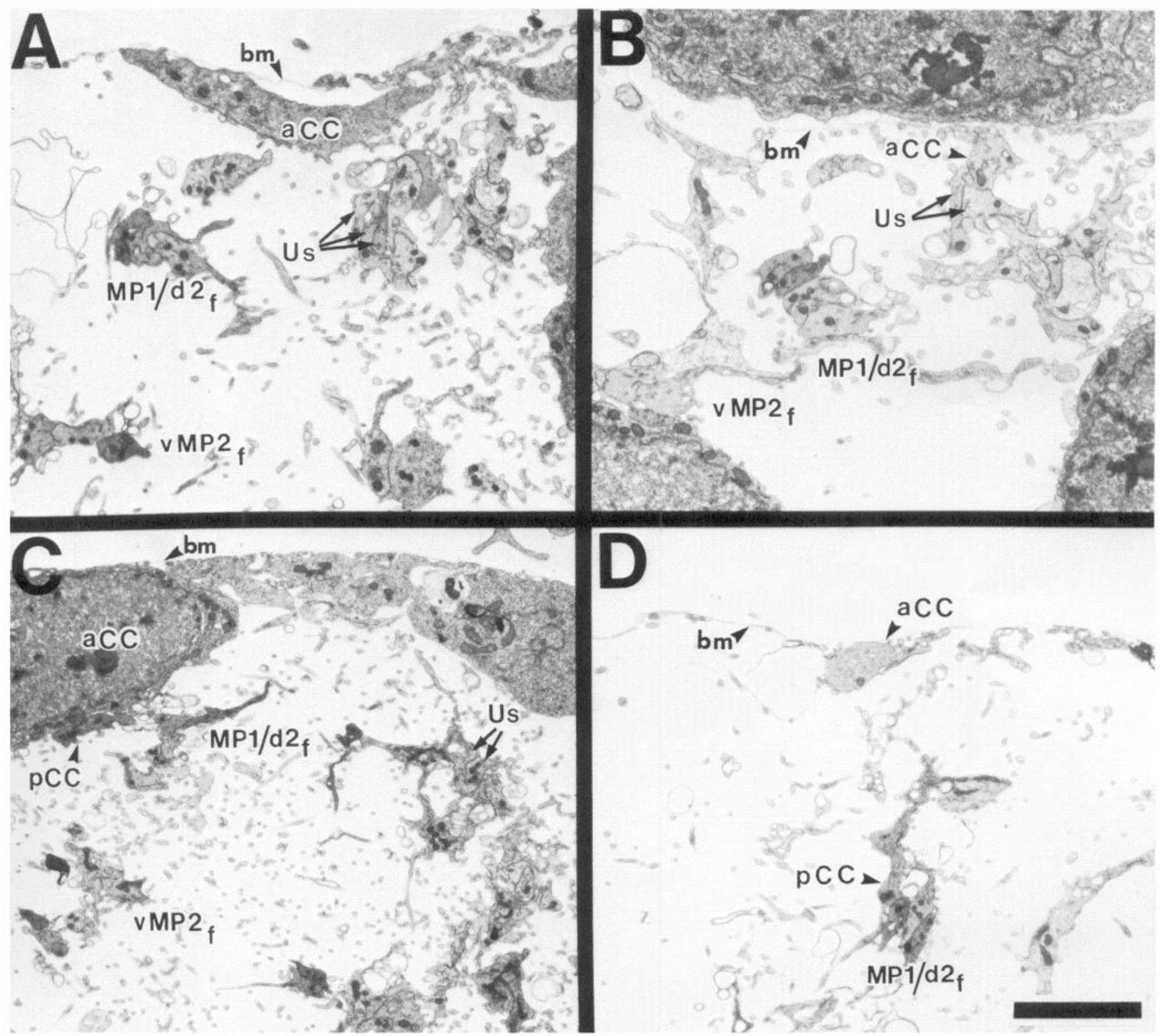

Figure 3. Transmission electron micrographs showing behavior of the delayed aCC neuron in 2 different experimental embryos, 1 from experiment $1(A, B)$ and the other from experiment $2(C, D) . A, B, \mathrm{~A}$ "younger" assay of an experiment 1 embryo in which the delayed $a C C$ growth cone had just turned posteriorly along the $\mathrm{U}$ fascicle $(U s)$. The $a C C$ first extends laterally just under the basement membrane $(b m)(A)$. The $a C C$ growth cone then turns posteriorly along the $U$ fascicle, also keeping contact with the basement membrane and/or processes just under it. At this stage, the $U$ fascicle is up just under the basement membrane, which itself is relatively clear of other processes. Each of the first 3 longitudinal fascicles $(f ; v M P 2, M P 1 / d M P 2$, and Us) contains a few additional axons. At this stage of development, a third $\mathrm{U}$ axon joins the initial $2 \mathrm{Us}$. $C$, $D$, In $50 \%$ of the experiment 2 embryos, the $a C C$ growth cone did not extend posteriorly as normal along the $\mathrm{U}$ fascicle $(C)$, but instead extended anteriorly along the basement membrane, as shown in $D$; in all experiments, the $p C C$ extended anteriorly along the $M P 1 / d M P 2$ fascicle $(f)$, as seen in $D$. Note that the $U$ fascicle is further ventral, the basement membrane is populated by glial cells, and additional axons in the $U$ fascicle have partially covered the U axons. For further details and discussion of implications, see text. Scale bar, $5 \mu \mathrm{m}$.

terestingly, the aCC growth cone left its contact with the U fascicle and instead grew separately along the surface of the SBC (Fig. $4 F$ ), the primitive glial cell that prefigures this nerve pathway (see paper III). Furthermore, the SBC processes partly enwrapped the aCC axon (Fig. $4 F$ ) several microns away from where they began to enwrap the main fascicle containing the three Us and other axons.

These data indicate that when the aCC and pCC neurons differentiated $10 \mathrm{hr}(2 \%)$ later than normal, (1) both neurons were able to recognize their appropriate axonal pathways within the developing CNS and (2) the aCC was able to recognize its appropriate glial pathway (the SBC) as it exited the CNS-all this despite the addition of many more axons and fascicles within the developing neuropil.

\section{Experiment 2}

To increase the delay in aCC and pCC differentiation, we ablated NB 1-1 $5 \mathrm{hr}$ later than in experiment 1 . In this experiment, both NB 1-1 and its first progeny (GMC-1) were ablated (Fig. $2 B$ ). The ablated NB was replaced; the new NB 1-1 generated a GMC1 , which divided to produce the $\mathrm{aCC}$ and $\mathrm{pCC}$ neurons. In this case, the generation of the aCC and pCC neurons was delayed 


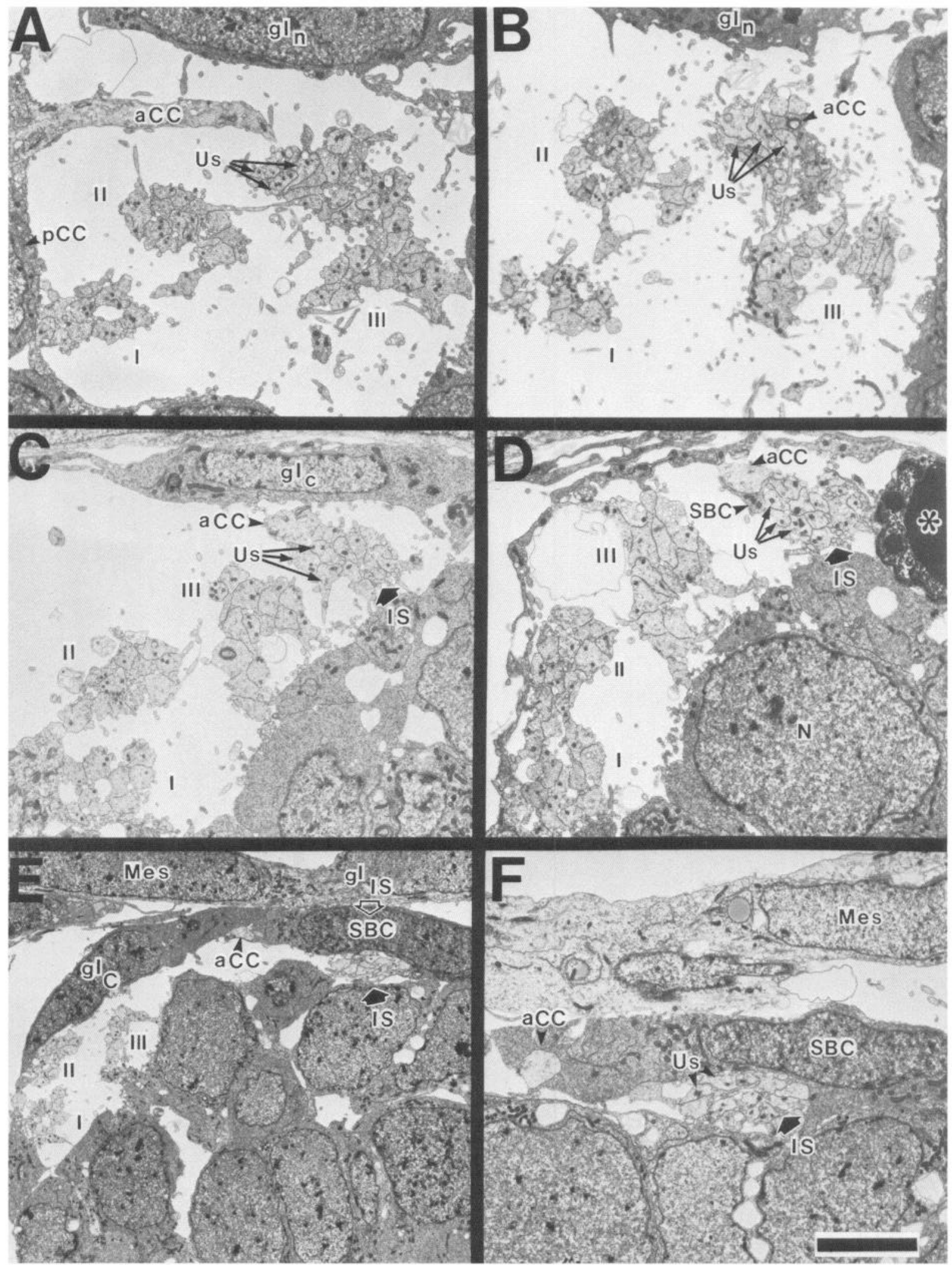

Figure 4. Representative electron micrographs from a semiserial-section reconstruction of an "older" experiment 1 embryo showing the delayed aCC neuron extending along its normal axonal and glial pathways. Five sections are shown, starting at the $a C C$ cell body $(A)$ and going to levels further posterior to the $I S$ nerve $(F) ; E$ and $F$ are the same section at different magnifications. The experiment 2 embryo shown here is $2 \%$ older than that shown in Figure 3, $A, B$. In this embryo the delayed $a C C$ growth cone has extended posteriorly and already turned laterally out the IS nerve. By this stage of development, the initial 3 fascicles in the connective have already begun to expand into the 3 superfascicles, $I$, $I I$, and $I I I$. Where the $a C C$ axon first joins the $\mathrm{U}(U s)$ fascicle anteriorly near its cell body $(A)$, it is in contact with the three $\mathrm{U}$ axons $(B, C)$. Further posteriorly, the aCC axon is in contact with a process of the segment boundary cell $(S B C)$, which, in turn, is in contact with the $3 \mathrm{U}$ axons $(D)$. The aCC axon 
by about $15 \mathrm{hr}(3 \%)$ compared with their normal time of generation (Doe and Goodman, 1985b).

Although confronted with even more axons and fascicles, the pCC growth cone always extended anteriorly along the MP1/ dMP2 fascicle. In $50 \%$ of these experimental embryos (11/22), the aCC growth cone extended along its normal pathway, the IS nerve of its own segment. However, in the other $50 \%$ of the experimental embryos of this paradigm, the aCC growth cone did not extend posteriorly, as normal, along the $U$ fascicle. Instead, the aCC growth cone extended anteriorly along the basement membrane (Fig. $3 D$ ), just above and within reach of many of the fascicles within the developing axon scaffold of the ganglionic neuropil (Fig. $2 B$ ). Although confronted with many new and different axon surfaces, it did not selectively fasciculate with any of them. Rather, once it had extended far enough anteriorly to contact its normal pathway from the next anterior segment (the IS nerve), it turned laterally and grew along this nerve. An example of 2 such embryos is shown in Figures $2 B$ and 5 (the asterisks in this and subsequent figures denote the delayed, compared with the normal, pCC and aCC neurons).

Why didn't the delayed aCC growth cone extend posteriorly along the $U$ fascicle as normal? There are 3 possibilities. (1) The aCC had changed and no longer displayed the same selective affinitics; (2) the $U$ axons had changed, and werc no longer selectively recognized by the aCC growth cone; (3) the $\mathrm{aCC}$ growth cone no longer had the same access to the surfaces of the $U$ axons as previously. The observations described below are addressed to this third alternative. (These 3 alternatives and their implications are considered in greater detail in the discussion.)

To study the possibility of the third alternative, a changing spatial environment, we examined an "early" embryo of this experimental paradigm in serial electron micrographs (Fig. 3, $C, D$ ) (by "early," we mean an embryo in which the aCC growth cone had just begun extending anteriorly along the basement membrane). At the level of the aCC cell body, 3 spatial aspects were different in this $3 \%$ delay experiment, compared with the $2 \%$ delay experiment described above. (1) Additional glial cells have populated the area just under the basement membane; (2) the $U$ fascicle has been displaced ventrally and is farther from the $\mathrm{aCC}$ and the basement membrane; (3) additional axons have fasciculated with the $U$ axons and partially cover them. These 3 changes in the spatial relationship between the aCC growth cone and the $\mathrm{U}$ axons are possibly of great significance, given the normal distribution of the aCC filopodia when it first contacts the U neurons, as shown in Figure 5 in paper II of this series.

Normally, the aCC filopodia radiate in a relatively planar halo around the cell body up near the dorsal basement membrane. Thus it is possible that the ventral displacement of the $U$ fascicle, coupled with both the greater glial covering of the basement membrane just lateral to the cell body and the partial covering of the $U$ axons themselves within the $U$ fascicle, leads to the $50 \%$ probability that the aCC growth cone will not contact the $\mathrm{U}$ axons but, rather, will begin to wander anteriorly.

We superimposed the pathways of 13 experimental embryos in which the aCC growth cone had wandered anteriorly and then turned laterally out the anterior IS nerve (Fig. 6). It is interesting to note that, in these experimental embryos, the aCC growth cone took a variety of routes anteriorly along the basement membrane, extending over regions ranging from the most medial part of the developing neuropil to its lateral edge. Along the way, the aCC contacted, but did not display a selective affinity for, the surfaces of many additional neurons, including RP1 and RP2, whose axons also extend out the IS nerve (RP1 and RP2 are siblings whose axons take very different routes to the same final pathway, albeit on different sides of different segment borders; the RP1 axon extends contralaterally, posteriorly, and then out the posterior contralateral IS; the RP2 axon extends anteriorly and then out the anterior ipsilateral IS). However, once the aCC growth cone gets within filopodial grasp of the IS nerve, it turns laterally along it. We do not know whether the aCC growth cone at this point is guided to turn along the IS nerve by its contact with specific axons (e.g., the $\mathrm{U}$ axons), specific glia (e.g., the SBC and its progeny), or both.

\section{Experiment 3}

To produce even greater delays in aCC and pCC differentiation, we ablated NB 1-1 (and often its second GMC) after its first 2 (or 3) divisions (Fig. 2C). The original GMC-1 divided to produce normal $\mathrm{aCC}$ and $\mathrm{pCC}$ neurons. The ablated NB 1-1 was replaced; the new NB 1-1 began its lineage afresh. Although delayed by some $20 \mathrm{hr}(4 \%)$ compared with normal, the regulated NB 1-1 nevertheless generated a new GMC-1, thus giving rise to a second (duplicate) pair of aCC and pCC neurons. Both pairs of aCC and pCC neurons survived and differentiated (Doe and Goodman, 1985b).

In all of the experimental embryos of this paradigm $(n=7)$, the normal pCC and aCC neurons and the duplicate pCC neuron extended axons in the normal direction along their normal pathways. However, the duplicate aCC neuron ( $4 \%$ delayed) always extended its axon anteriorly along the basement membrane and then laterally along the anterior IS nerve (Fig. 2C), just as it did in $50 \%$ of the experimental embryos of experiment 2 . An example of such an experimental embryo is shown in Figure 7.

The results of experiment 3 further confirm the results of experiment 2 , and, in addition, make 2 other points. First, the embryos are another $1 \%$ older (compared with those of experiment 2) and, thus, even more axons and fascicles have added to the ganglionic neuropil (see Fig. 8 for an example of the complexity of the neuropil at this stage). Nevertheless, the aCC growth cone did not fasciculate with other axons, but rather extended anteriorly along the basement membrane until it contacted the IS nerve. Second, although the duplicated aCC neuron sat right above the original aCC neuron whose axon extended into the connective and then along the appropriate pathway, the growth cone from the duplicated aCC did not follow the original aCC"s axon to the $U$ fascicle; that is, the aCC did not follow itself. This is surprising, and suggests that the cell body and initial axon segment of the aCC may not express the appropriate surface label.

\section{Discussion}

In this paper, we use laser ablations of a specific neuronal precursor cell (NB 1-1) in ovo and its subsequent regulation by neighboring undifferentiated nECs (Doe and Goodman, 1985b) to specifically delay the development of the aCC and $\mathrm{pCC}$ neurons and their growth cones compared with other axons in the embryonic neuropil. The results of these temporal delay experiments further demonstrate the absolute specificity of the pCC growth cone for the MP1/dMP2 fascicle, and of the aCC growth cone for the $U$ fascicle and IS nerve, even when confronted with

turns laterally along the pathway of the IS nerve $(E)$, while the 3 superfascicles, I, II, and III, continue longitudinally to the next segment. The aCC growth cone leaves its contact with the U fascicle and instead grows separately along the surface of the SBC $(F)$. The SBC processes partly enwrap the aCC axon $(F) . g l_{n}$, Glia of the neuropil; $g l_{c}$, connective glia; $g l_{I S}$, glia of the intersegmental nerve (e.g., the SBC); $M e s$, mesodermal cell; $N$, neuronal cell body. Scale bar, $5 \mu \mathrm{m}(A-D, F) ; 10 \mu \mathrm{m}(E)$. 


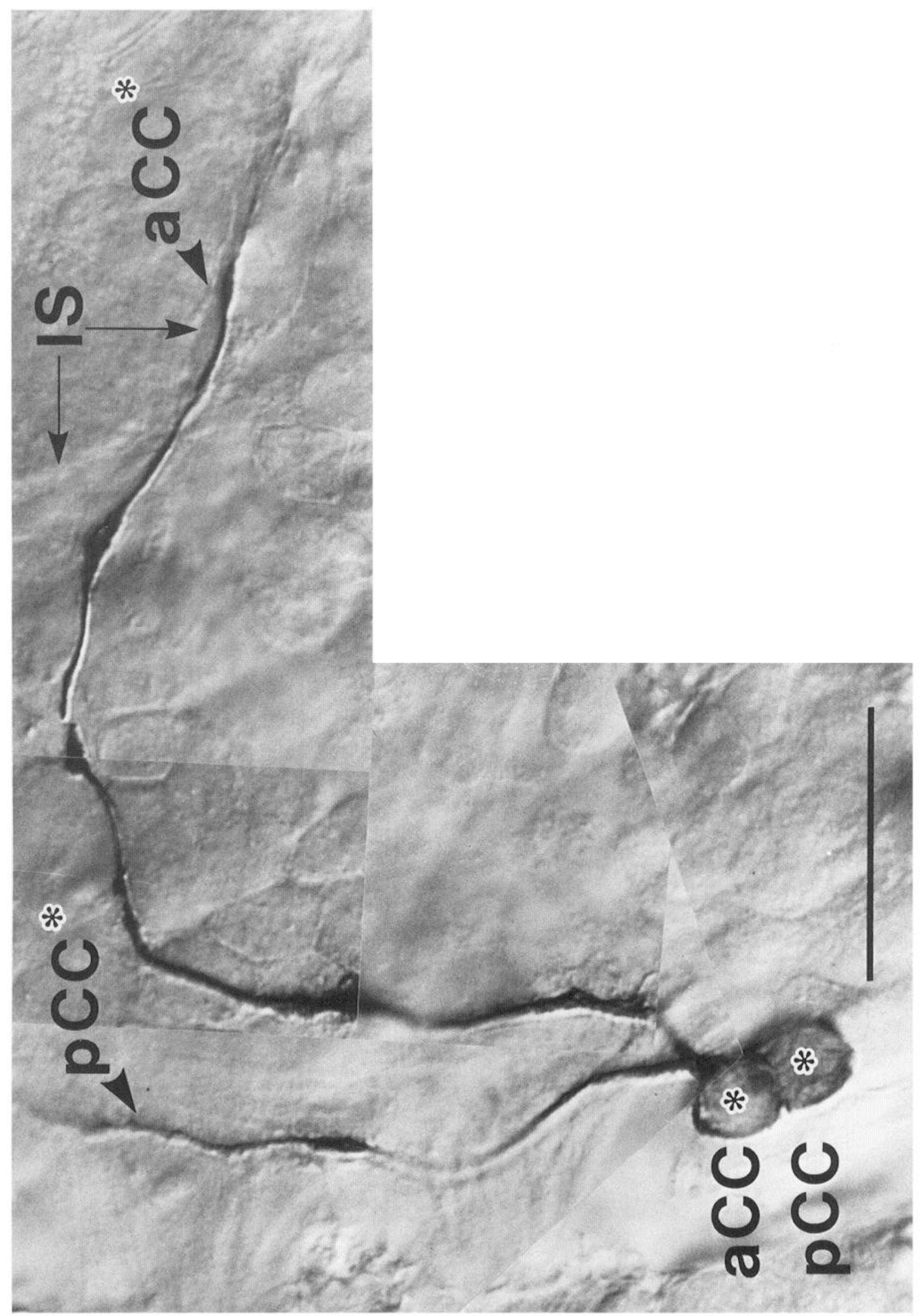

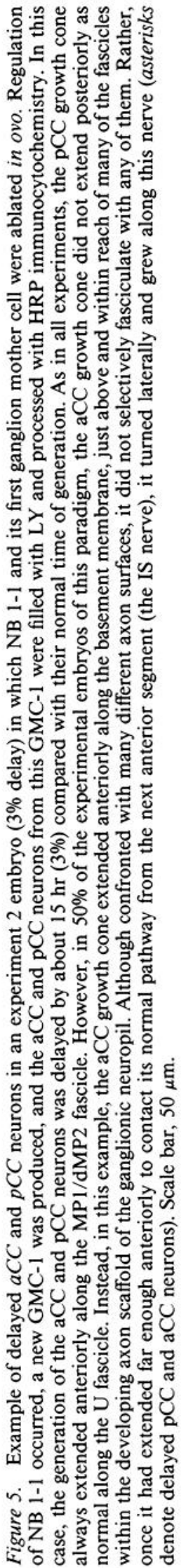


many additional axons and altered spatiotemporal relationships.

The experimental results presented in the first 2 papers of this series argue against both the simple location of axons and the simple timing of axon outgrowth as being the major determinants in the pathway choice of a growth cone. The results described here extend these same arguments to greatly altered temporal and spatial relationships.

In all of the embryos of experiments $1-3$, which delayed the pCC and aCC neurons by 2,3 , and $4 \%$ of development, respectively, the pCC growth cone always extended anteriorly along its normal pathway, the MP1/dMP2 fascicle (Fig. 9). Given the temporal delay and increased complexity of the developing neuropil, the bchavior of the pCC growth cone in these experiments presents the clearest argument that precise temporal and spatial relationships are not important so long as the growth cone can make contact with its appropriate pathway.

However, the behavior of the aCC growth cone was not so simplc (Fig. 9). In all of the embryos of experiment 1, only $50 \%$ of the embryos of experiment 2 , and none of the embryos of experiment 3 , the aCC growth cone extended posteriorly as normal along the $U$ fascicle, and, where old enough to assay, laterally out the IS nerve.

The question is, Why doesn't the aCC growth cone follow its normal pathway in the remainder of the $3 \%$ (experiment 2 ) and in any of the $4 \%$ (experiment 3 ) delay experiments? There are 3 possibilities. (1) The aCC has changed and no longer displays the same selective affinities. The fact that the aCC does not fasciculate with any other axons, and then correctly recognizes the IS nerve when it contacts it, argues against this alternative. (2) The $U$ axons have changed and can no longer be selectively recognized by the aCC growth cone. One might imagine that the surface of the $U$ axons changes over time, perhaps as a result of its intrinsic age (i.e., distance from the growth cone) and/or extrinsic modifications by other cells. Normally, the aCC growth cone extends along the U axons close to their growth cones (and thus presumably along younger membrane), whereas, in the longer experimental delays, the aCC growth cone contacts progressively older axons that are farther from the growth cone. At present, no data argue for or against this alternative. (3) The aCC growth cone no longer has the same access to the surfaces of the $U$ axons as previously. Detailed observations of several experimental embryos support, although by no means prove, this alternative. In these longer delay experiments, additional glial cells populate the area just under the basement membrane, the $U$ fascicle becomes displaced farther ventrally and is no longer as close to the dorsal basement membrane, and additional axons fasciculate with the $U$ axons and partially cover them. Given the normally planar radiation of the aCC filopodia dorsally near the basement membrane (see Fig. 5 in paper II), these spatial changes might lead to either qualitative or quantitative differences in the contacts between the aCC filopodia and the $\mathrm{U}$ axons, thus preventing the aCC growth cone from interacting normally with the U axons and following them out the IS nerve.

Finally, these results further highlight the dual affinities of neuronal growth cones for both specific axonal pathways (papers I and II) and specific glial pathways (paper III). In experiment 1 , the aCC growth cone extended posteriorly as normal along the $\mathrm{U}$ fascicle, then turned laterally as normal along the IS nerve pathway. Although delayed by $2 \%$ of development, and although many additional axons had joined the $U$ fascicle, the aCC growth cone nevertheless left the $U$ fascicle and grew separatcly along the SBC (an identified glial cell) as it normally does. Moreover, the SBC began to enwrap the aCC axon quite separately from the $U$ fascicle. These findings further point to the specificity of

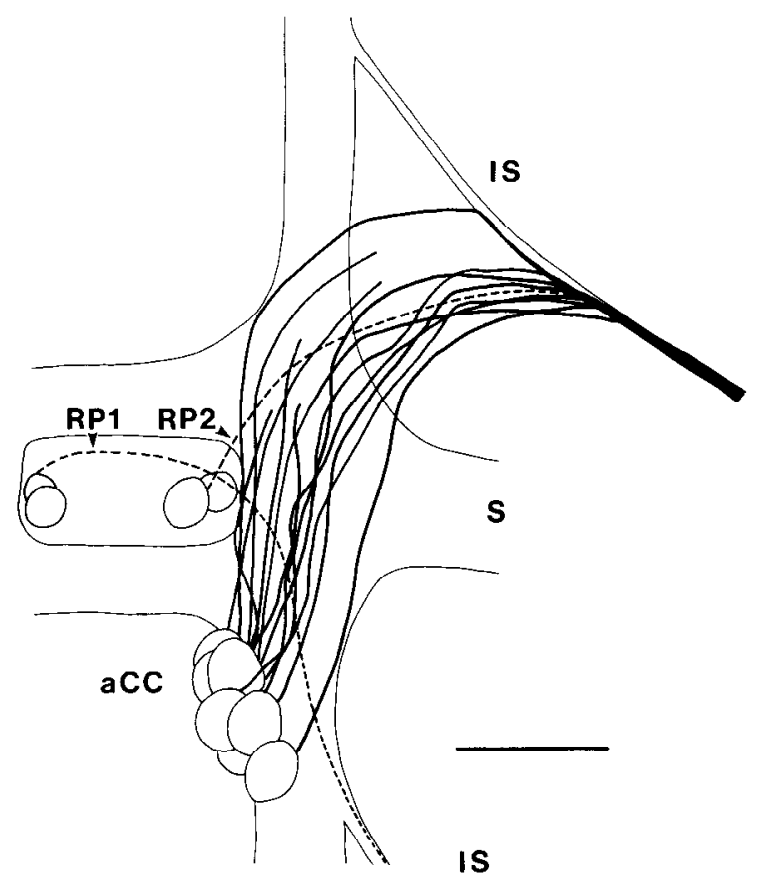

Figure 6. In temporal delay experiments, the anterior extending $a C C$ growth cone shows affinity only for the IS nerve. Superimposed is the pathway of 13 delayed aCC neurons from experiment 2 and 3 embryos in which the aCC growth cone wandered anteriorly and then turned laterally out the anterior IS nerve. Note that the aCC bypasses the RPI and $R P 2$ neurons, both of whose axons take different pathways to exit out the $I S$ nerve. $S$, Segmental nerve. For discussion, see text. Scale bar, $50 \mu \mathrm{m}$.

the interactions between this glial cell and the aCC growth cone and axon.

Thus, in the temporal delay experiments, the pCC growth cone always found its correct pathway, whereas the aCC did not. This may be explained by the fact that, during this period of development, the MP1/dMP2 fascicle increases in size, in part because of the addition of many homologous MP1 and dMP2 axons from more anterior segments (which, as shown in paper $I$, provide the same guidance cue). By contrast, the $U$ fascicle is not a longitudinally continuous pathway, and thus, as it enlarges, it still contains only the original set of $U$ axons.

Interestingly, in those experimental 2 and 3 embryos in which the aCC growth cone did not extend posteriorly as normal along the $U$ fascicle, it always extended anteriorly under the basement membrane until it contacted the IS nerve from the next anterior segment (e.g., Fig. 6). Although the aCC growth cone in these experimental embryos always extended in the same general direction (anteriorly), we have no idea why it did so. Clearly, something, such as the basement membrane or possibly the primitive glial cells just under it, must have been providing some sort of polarity information. But we do not understand why, in the absence of the normal axonal pathway that guides it posteriorly, the aCC growth cone made a specific polarity decision to extend in the opposite direction along a non-neuronal substrate.

We do not know how long in development the axonal and glial pathways we have described in these papers would continuc to express their specific surface labels. All that the experiments described here tell us is that $4 \%$ of development later (and after the addition of more than 50 axons in each hemisegment), the 


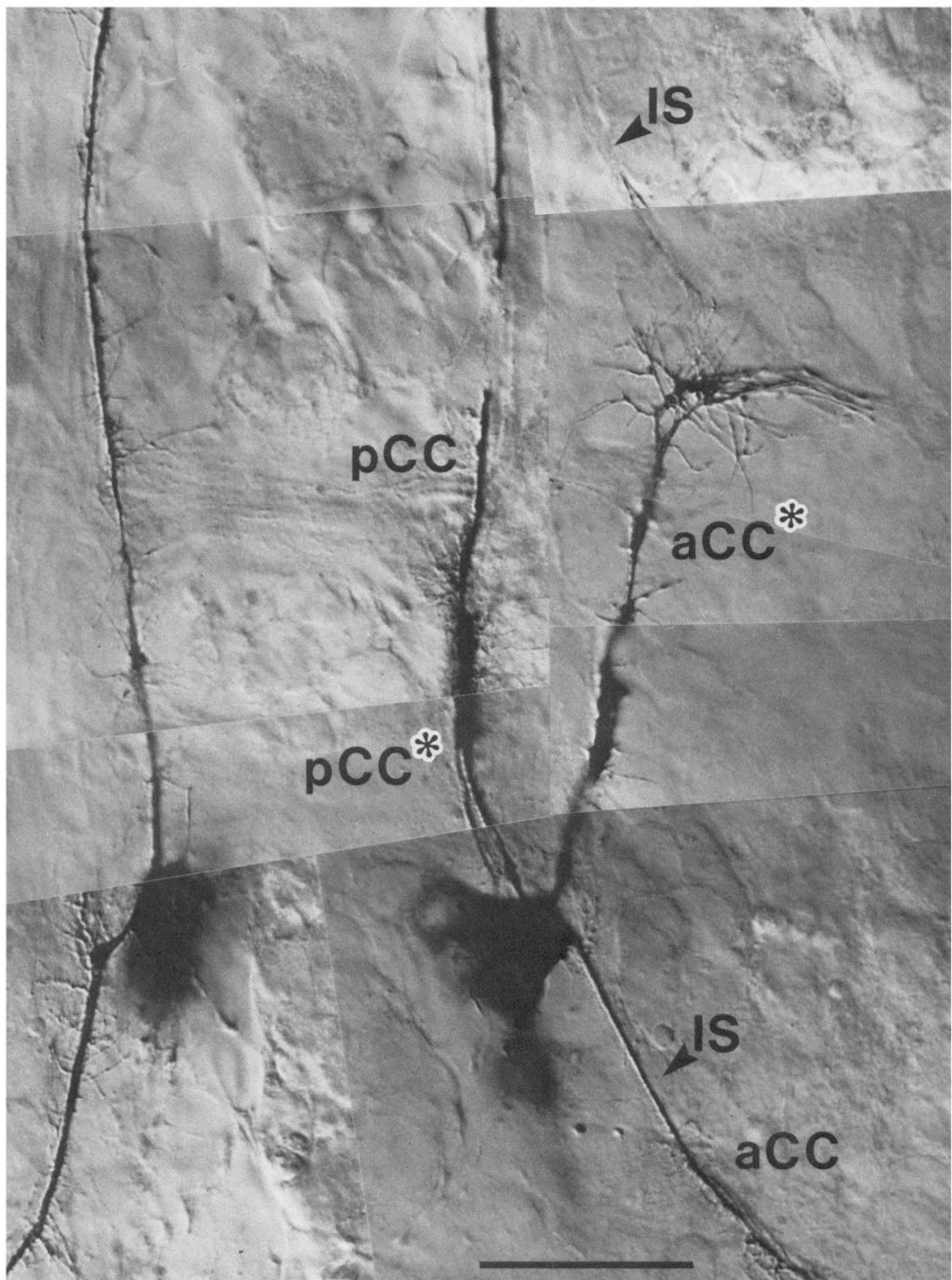

Figure 7. An experiment 3 embryo showing both normal and delayed (duplicate) $a C C$ and $p C C$ neurons. In this embryo, NB 1-1 and its second GMC on the right side were ablated in ovo after its first 2 divisions; a new NB 1-1 was formed and produced the delayed (20 hr, $4 \%$ ) duplicate $\mathrm{aCC}$ and pCC neurons. On the left (control) side, normal $\mathrm{aCC}$ and $\mathrm{pCC}$ neurons were produced. The aCC and pCC neurons on both sides of the segment were filled with LY and processed with HRP immunocytochemistry. The normal aCC and pCC neurons and the duplicate pCC neuron (asterisk) extended axons along their normal pathways. However, the duplicate aCC neuron (4\% delayed; asterisk) extended its axon anteriorly along the basement membrane and then turned laterally along the anterior IS nerve. Interestingly, the delayed aCC did not follow the original aCC, whose cell body is directly below it. The gap in the pCC axon on the right is an artifact of the histological processing of the embryo. Scale bar, 50 $\mu \mathrm{m}$. 


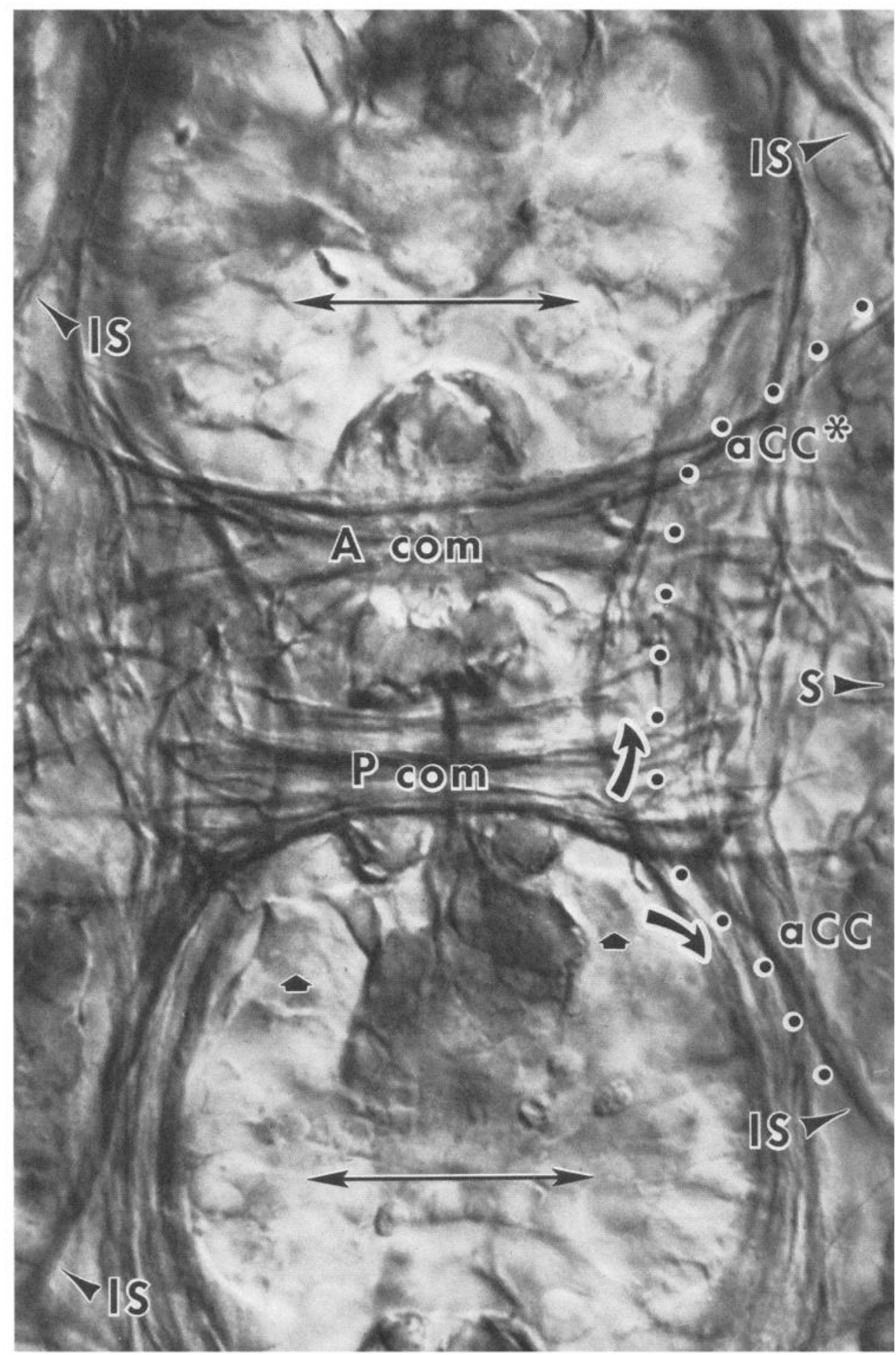

Figure 8. Normal and abnormal pathways of $a C C$ growth cone in temporal delay experiments. In experiment 3 embryos, the $a C C$ neuron was delayed by $20 \mathrm{hr}$. Whereas normally it confronts an environment of 3 fascicles and 6 other axons, when delayed by $20 \mathrm{hr}$ it confronts an environment like the one shown here. Nevertheless, the delayed aCC neuron wanders anteriorly along the basement membrane (asterisk), bypassing many other axons, before turning laterally out the IS nerve from the next anterior segment. This photograph shows the orthogonal scaffold of axon fascicles in the developing neuropil of a single segment of the grasshopper embryo at $40 \%$ of development, as viewed from the dorsal surface of the wholemount neuroepithelium, stained with the I-5 mAb and prepared for HRP immunocytochemistry. At this stage of development, the scaffold contains about 100 axons on each side (hemisegment), organized into 25 longitudinal axon fascicles. Each segmental unit also contains 3 lateral commissures joining the 2 hemisegments ( 1 posterior and 2 fused anterior) and 2 peripheral nerve pathways on each side, the IS nerve at the segment boundary, and the segmental $(S)$ nerve at the segment midline. Horizontal line with arrows denotes segment border and acts as a scale bar (100 $\mu \mathrm{m})$; small arrowheads mark aCC cell bodies. 

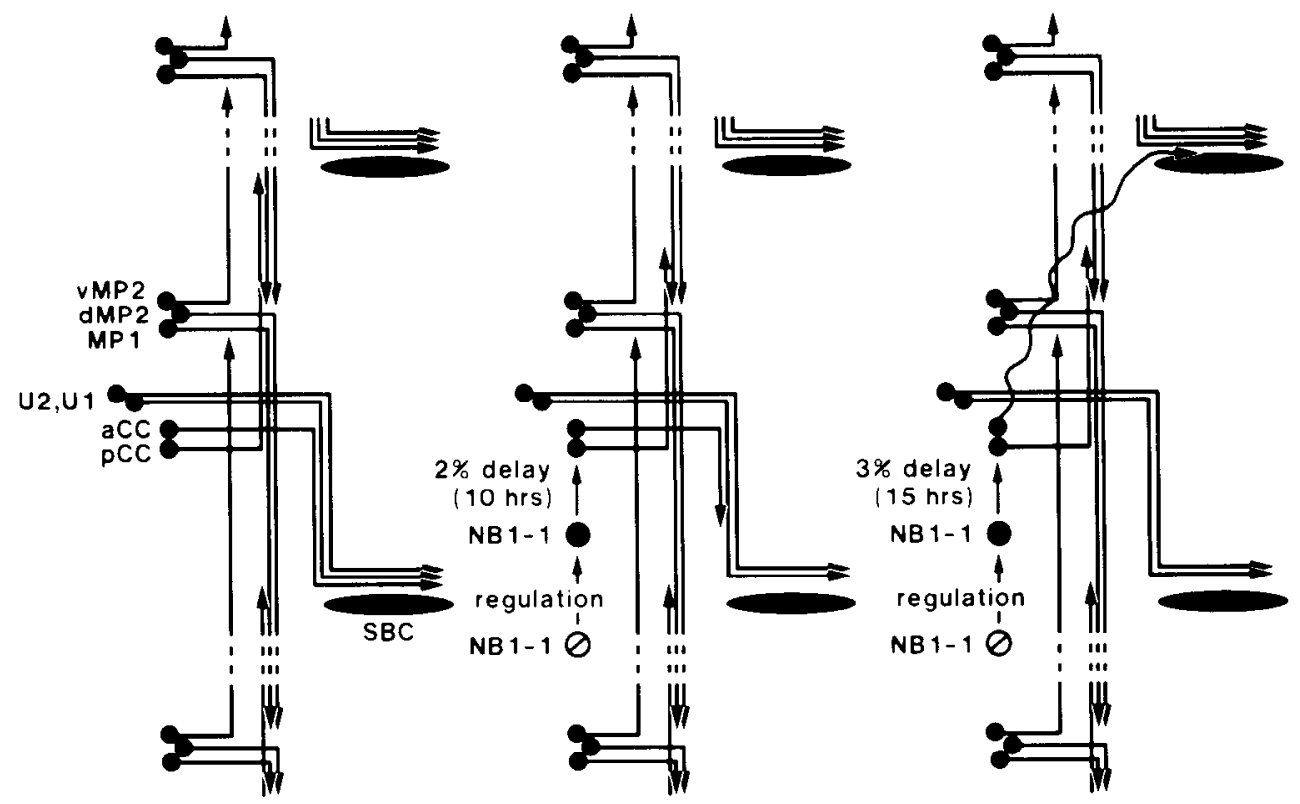

Figure 9. Schematic diagram illustrating results of temporal delay experiments in which laser ablations of $N B I-I$ in ovo and its subsequent regulation by neighboring, undifferentiated neural ectodermal cells (nECs) were used to specifically delay the development of the $a C C$ and $p C C$ neurons and their growth cones as compared with other axons in the developing neuropil. On the left are the first 3 longitudinal axon fascicles, the IS nerve, and the 7 axons they initially contained. Also shown is the segment boundary cell $(S B C)$, the primitive glial cell that is part of a preformed glial pathway for the IS nerve. In the middle are the results of experiment 1 , in which the delayed aCC and pCC neurons followed their normal pathways. On the right are the results of $50 \%$ of the embryos of experiment 2 , in which the delayed pCC neuron followed its normal pathway but the delayed aCC neuron wandered anteriorly until it contacted the IS nerve from the next anterior segment; in the other $50 \%$ of these embryos, the aCC neuron followed its normal pathway. These results further demonstrate the absolute specificity of the pCC growth cone for the $M P 1 / d M P 2$ fascicle and of the aCC growth cone for the $U$ fascicle and the IS nerve, even when confronted with additional axons, pathways, and altered spatiotemporal relationships. For a discussion, see text.

pCC and aCC growth cones can still distinguish their appropriate pathways. The experimental paradigm used here, namely, laser ablation and subsequent regulation of a neuronal precursor cell, does not allow for experiments with longer delay times. But even these $2-4 \%$ delays suggest that absolute timing is not the major determinant in pathway selection, but rather that surface specificities govern these choices. These conclusions are similar to those derived from similar experiments on the development of neuromuscular specificity in the chick hindlimb (Lance-Jones and Landmesser, 1980a, b, 1981a, b), and suggest the possibility of similar mechanisms underlying growth-cone guidance in these 2 organisms of diverse phyletic origin.

\section{References}

Bastiani, M. J., and C. S. Goodman (1986) Guidance of neuronal growth cones in the grasshopper embryo. III. Recognition of specific glial pathways. J. Neurosci. 6: 3542-3551.

Bastiani, M. J., K. G. Pearson, and C. S. Goodman (1984a) From embryonic fascicles to adult tracts: Organization of neuropil from a developmental perspective. J. Exp. Biol. 112: 45-64.

Bastiani, M. J., J. A. Raper, and C. S. Goodman (1984b) Pathfinding by neuronal growth cones in grasshopper embryos. III. Selective affinity of the $G$ growth cone for the $P$ cells within the $A / P$ fascicle. $J$. Neurosci. 4: 2311-2328.

Bastiani, M. J., C. Q. Doe, S. L. Helfand, and C. S. Goodman (1985) Neuronal specificity and growth cone guidance in grasshopper and Drosophila embryos. Trends Neurosci. 8: 257-266.

Bastiani, M. J., S. du Lac, and C. S. Goodman (1986) Guidance of neuronal growth cones in the grasshopper embryo. I. Recognition of a specific axonal pathway by the pCC neuron. J. Neurosci. 6: 35183531 .

Bate, C. M. (1976) Embryogenesis of an insect nervous system. I. A map of the thoracic and abdominal neuroblasts in Locusta migratoria. J. Embryol. Exp. Morphol. 35: 107-123.
Doe, C. Q., and C. S. Goodman (1985a) Early events in insect neurogenesis: I. Development and segmental differences in the pattern of neuronal precursor cells. Dev. Biol. 111: 193-205.

Doe, C. Q., and C. S. Goodman (1985b) Early events in insect neurogenesis: II. The role of cell interactions and cell lineage in the determination of neuronal precursor cells. Dev. Biol. 111: 206-219.

Doe, C. Q., J. Y. Kuwada, and C. S. Goodman (1985) From epithelium to neuroblasts to neurones: The role of cell interactions and cell lineage during insect neurogenesis. Philos. Trans. R. Soc. Lond. [Biol.] 312: $67-81$.

du Lac, S., M. J. Bastiani, and C. S. Goodman (1986) Guidance of neuronal growth cones in the grasshopper embryo. II. Recognition of a specific axonal pathway by the aCC neuron. J. Neurosci. 6: 35323541 .

Goodman, C. S., and N. C. Spitzer (1979) Embryonic development of identified neurones: Differentiation from neuroblast to neurone. Nature 280: 208-214.

Goodman, C. S., J. A. Raper, R. K. Ho, and S. Chang (1982) Pathfinding of neuronal growth cones in grasshopper embryos. In Developmental Order: Its Origin and Regulation, S. Subtelny and P. B. Green, eds., pp. 275-316, Liss, New York.

Goodman, C. S., M. J. Bastiani, C. Q. Doe, S. du Lac, S. L. Helfand, J. Y. Kuwada, and J. B. Thomas (1984) Cell recognition during neuronal development. Science 225: 1271-1279.

Kuwada, J. Y., and C. S. Goodman (1985) Neuronal determination during embryonic development of the grasshopper nervous system. Dev. Biol. 110: 114-126.

Lance-Jones, C., and L. Landmesser (1980a) Motoneurone projection patterns in embryonic chick limbs following partial deletions of the spinal cord. J. Physiol. 302: 559-580.

Lance-Jones, C., and L. Landmesser (1980b) Motoneurone projection patterns in the chick hind limb following early partial reversals of the spinal cord. J. Physiol. 302: 581-602.

Lance-Jones, C., and L. Landmesser (1981a) Pathway selection by chick lumbrosacral motoneurons during normal development. Proc. R. Soc. Lond. [Biol.] 214: 1-18. 
Lance-Jones, C., and L. Landmesser (1981b) Pathway selection by embryonic chick motoneurons in an experimentally altered environment. Proc. R. Soc. Lond. [Biol.] 214: 19-52.

Raper, J. A., M. J. Bastiani, and C. S. Goodman (1983a) Pathfinding by neuronal growth cones in grasshopper embryos. I. Divergent choices made by the growth cones of sibling neurons. J. Neurosci. 3: 20-30.

Raper, J. A., M. J. Bastiani, and C. S. Goodman (1983b) Pathfinding by neuronal growth cones in grasshopper embryos. II. Selective fasciculation onto specific axonal pathways. J. Neurosci. 3: 31-41.

Raper, J. A., M. J. Bastiani, and C. S. Goodman (1983c) Guidance of neuronal growth cones: Selective fasciculation in the grasshopper embryo. Cold Spring Harbor Symp. Quant. Biol. 48: 587-598.
Raper, J. A., M. J. Bastiani, and C. S. Goodman (1984) Pathfinding by neuronal growth cones in grasshopper embryos. IV. The effects of ablating the $A$ and $P$ axons upon the behavior of the $G$ growth cone. J. Neurosci. 4: 2329-2345.

Taghert, P. H., and C. S. Goodman (1984) Cell determination and differentiation of identified serotonin-immunoreactive neurons in the grasshopper embryo. J. Neurosci. 4: 989-1000.

Wheeler, W. M. (1893) A contribution to insect embryology. J. Morphol. 8: 1-160. 